\title{
Stress and wellbeing in prison officers
}

\section{Introduction <a>}

Prison officers are at greater risk of work-related stress than most other occupations in the United Kingdom (UK) (Johnson et al., 2005). The rates of mental health problems and burnout in the profession are also comparatively high (Kinman et al., 2016; Kunst, 2011). Challenges to the wellbeing of prison staff include heavy workloads, lack of autonomy and support, low resources, role stressors and exposure to aggression and violence (Finney et al,. 2013). In this chapter we draw on research conducted by ourselves and others that identifies the key stressors experienced by UK prison officers and the implications for their wellbeing and job performance. Particular focus is placed on our research that has utilized the Health and Safety Executive Management Standards framework to diagnose the psychosocial hazards experienced by prison staff, but other stressors, such as personal experiences of aggression and violence, poor work-life balance and recovery opportunities and presenteeism, are also considered. We argue that carefully targeted, multi-level interventions are needed to address the challenges faced by the sector and identify priorities for future research.

\section{Prisons in crisis <a>}

Prison officers experience particularly high levels of job-related stressors that can threaten their wellbeing and effectiveness. The work is intrinsically stressful and emotionally demanding, as they are responsible for the safeguarding and rehabilitation of offenders whose behaviour may be resistant, unpredictable or violent. Adequate numbers of welltrained officers are therefore required to ensure the wellbeing and safety of staff and prisoners. Nonetheless, at the time of writing this chapter, around two-thirds of prisons in the UK are categorised as overcrowded and many are under-staffed, with serious implications for the wellbeing of prisoners and staff (House of Commons Library, 2018; Prison Reform 
Trust, 2017). The impact on prisoners has been highlighted by the findings of a recent assessment of four key areas of prisoner wellbeing (safety, respect, purposeful activity and rehabilitation, and planning for release), where 46 per cent of institutions in the UK performed poorly (Ministry of Justice, 2018a). A major concern is the amount of time prisoners spend in purposive activity, with one in five being unlocked for less than two hours a day due to short-staffing (HM Chief Inspector of Prisons for England and Wales, 2018). Although recent recruitment efforts have to some extent been successful, the annual turnover rate has risen especially among recent recruits (Ministry of Justice, 2018b).

\section{A stressful occupation $<a>$}

Based on responses from more than 25000 individuals across 26 occupations, Johnson et al. (2005) found that prison officers reported worse than average scores for psychological wellbeing, physical health and job satisfaction. Although new research is needed at a national level to confirm these findings, it is unlikely that the wellbeing in the sector has improved over time. Several more recent studies have indeed found that prison officers have an elevated risk of burnout and post-traumatic stress disorder (PTSD) and a high proportion has been found to experience mental health problems at a level where intervention is recommended (Denhof \& Spinaris, 2013; Finney et al., 2013; Kinman et al., 2016). Mental health is discussed later in this chapter.

A systematic review conducted by Finney and colleagues (2013) identified a range of workrelated stressors experienced by prison officers. Characteristics of inmates are a key source of stress, with officers who work with dangerous prisoners being at greater risk (Misis et al., 2013). One of the most commonly-reported hazards is prisoner-on-staff assault which has risen considerably in recent years (Ministry of Justice, 2018c). Officers experience different types of aggression ranging from serious attacks requiring hospitalisation to verbal abuse "potting", (the throwing of excrement and verbal abuse) (Crown Prosecution Service, 2018). Research conducted by Kinman et al. (2014) examined the extent to which 1682 officers 
experienced six types of aggressive behaviours from prisoners. The most common behaviours were verbal abuse and threats, but 30 per cent of respondents had been physically assaulted, with more than one in four taking time off work to recover. The support provided by employers to help staff cope with such incidents was generally considered to be poor and those who had been assaulted were at greater risk of mental health problems (Kinman et al., 2014; Kinman et al., 2016).

The increasing rates of prisoner self-harm, as well as the threat of physical assault, have left staff vulnerable to PTSD (Boudoukha et al., 2013; Wright et al., 2006). Indeed there is evidence from the United States (US) that prison staff are at similar risk of PTSD as war veterans (James \& Todak, 2018). Officers need to be constantly alert to potential threats to their own wellbeing and that of prisoners that poses a risk to their mental and physical health (Fritz et al., 2018). The impact of the sustained need for 'hyper-vigilance', particularly in under-staffed and over-crowded prisons in the UK, should be further examined.

Low staffing levels and overcrowding in prisons have been identified as a major source of work-related stress (Martin et al., 2012). A larger prison population will intensify workload and time pressure among staff, as well as potentially increase the likelihood of adverse incidents. As discussed above, unsafe staffing levels also limit the time for prisoners to spend in purposive activity (HM Chief Inspector of Prisons for England and Wales, 2018). It has also been argued that the increased use of new psychoactive substances (NPS), such as Spice, among prisoners is partly a way of coping with boredom (Ralphs et al., 2017). Drug use is also widely believed to trigger much of the recent increase in prison violence in the UK (HM Chief Inspector of Prisons for England and Wales, 2016). Research conducted by Norton (2016) has highlighted the additional strain on staff caused by prisoners' unpredictable reactions to the drug and disruption to the prison regime.

Prison officers experience other occupationally-specific stressors. Negative depictions of prison officers' work by the media, and the public more generally, can contribute to burnout and job dissatisfaction (Vickovic et al., 2013). Emotional labour, defined as the effort 
involved in regulating feelings and expressions to fulfil the emotional requirements of a particular job, is an additional hazard for prison officers. Prisons have been described as emotionally-charged institutions (Crawley, 2004) and staff are required to manage their own emotions - including responses to people who have performed acts they may find repellent - and the emotional states of prisoners (Nylander et al., 2011). Managing the fear engendered by working in unpredictable and often dangerous conditions could be considered a form of emotional labour. Prison officers who report feeling fearful more regularly tend to experience more stress and be more likely to quit (Stichman \& Gordon, 2014). Insight into how fear can be reduced under such potentially hazardous working conditions is therefore required. A study of 40 US institutions by Gordon and Baker (2017) found that low staffing levels, poor organization and a culture of cynicism intensified fear among officers, whereas feelings of belongingness and transformational leadership inhibited it.

As well as occupationally-specific threats to their wellbeing, prison officers also experience more 'generic' stressors (Finney et al., 2013). Officers work long and antisocial hours, but a meta-analysis conducted by Dowden and Tellier (2004) failed to find a link between shift work and stress. It is likely that working shifts is considered 'just part of the job' and less hazardous than other factors that can compromise safety, such as exposure to violence and overcrowding. This analysis was published 15 years ago, however, and drew upon studies that are even older. More research is therefore needed to examine the effects of working hours under current conditions while considering the context and the type of work performed. For example, long hours spent supervising prisoners in an over-crowded high security prison are likely to be more hazardous to wellbeing than working overtime in an open prison where risks are typically low. Prison officers also tend to report low control over how their work is organized and their influence over decision-making (Dowden \& Tellier, 2004; Steiner \& Wooldredge, 2015). Several studies have also highlighted role difficulties as being particularly stressful for prison officers: for example, although role clarity appears to be high 
they may experience conflict and ambiguity stemming from competing views about the role of prison as punitive or rehabilitative (Finney et al., 2013; Lambert et al., 2011).

\section{Health and Safety Executive Management Standards <a>}

The UK Health and Safety Executive ([HSE], 2017) Management Standards framework was designed to help organizations monitor and manage wellbeing at work. It follows the principle that preventative approaches that assess risk are more effective in reducing workrelated stress than relying exclusively on individually-focused initiatives (Cousins et al., 2004). In our own research, described below, we adopted this framework to identify priorities for intervention within the UK prison service. The HSE has developed a measure, the Management Standards Indicator Tool (MSIT), which has been validated at the individual (Cousins et al., 2004) and organizational (Edwards et al., 2008) levels. The measure has been used in many organizations and sectors and benchmarks are available to compare organizational performance against specified targets (see Webster \& Buckley, 2008). The MSIT measures the following seven hazard categories (examples listed):

1. Demands - the quantity and pace of work

2. Control - the extent of worker autonomy

3. Manager support - listening to concerns, providing encouragement

4. Peer support - helping face challenges

5. Relationships - conflict at work

6. Role - role clarity

7. Change - change management and consultation

Mean scores for each of the hazard categories are compared with benchmarks to identify if: a) urgent action is needed (scores are below the $20^{\text {th }}$ percentile); b) clear need for improvement (scores below average, but not the $20^{\text {th }}$ percentile); c) good, but some need for improvement (better than average, but does not reach the $80^{\text {th }}$ percentile) and d) doing well (but needs to maintain performance). 
A previous study by Bevan et al. (2010) administered the MSIT and a measure of exhaustion to 1038 UK prison service employees. Of the seven categories, six were identified as needing improvement, whereas the seventh - job demands - was of less concern, but still required attention. Participants who perceived their psychosocial working conditions to be poor were at three-times the risk of exhaustion than those who viewed them more positively. Reflecting the importance of role difficulties as a source of stress for prison staff, role difficulties had the strongest effects on exhaustion. These were useful findings, as priorities were identified for intervention, but the participants included non-operational staff and the prisons sampled were restricted to the London area.

Our own study (Kinman et al., 2014; 2017) gathered responses from 1682 prison officers across the UK, although most (90 per cent) worked in prisons in England. As well as the MSIT, a widely-used measure of mental health (General Health Questionnaire (GHQ): Goldberg, 1978) was administered to identify the hazard categories most detrimental to wellbeing. Our findings differed from those of Bevan and colleagues in that six out of seven hazard categories required urgent attention: demands, control, manager support, relationships, role, and change. Peer support, while not requiring urgent attention, nevertheless needed some improvement. The hazard categories with the strongest effects on mental health were relationships $(\beta=-.26)$, demands $(\beta=.24)$, role $(\beta=-.17)$, control $(\beta=-$ $.07)$ and management of change $(\beta=-.06)$. Unexpectedly, support from managers or peers was not a significant predictor of mental health status. Although a wide range of difficulties was highlighted, of particular note was that four out of ten participants reported being bullied sometimes, often, or always at work.

Table 1: Comparison of survey findings with targets

\begin{tabular}{|l|l|l|l|}
\hline & Kinman et al & HSE target group & HSE target \\
\hline
\end{tabular}




\begin{tabular}{|l|c|c|c|}
\hline & (2016) & mean (with shortfall) & \\
\hline Demands & 1.88 & $3.44(-1.56)$ & 3.50 \\
\hline Control & 2.39 & $3.32(-.93)$ & 3.50 \\
\hline Manager & 2.57 & $3.77(-1.20)$ & 3.80 \\
\hline support & & & 4.00 \\
\hline Relationships & 2.75 & $4.13(-1.38)$ & 4.25 \\
\hline Role & 3.58 & $4.61(-1.03)$ & 5.00 \\
\hline Change & 2.21 & $3.54(-1.33)$ & 3.67 \\
\hline
\end{tabular}

Note: higher scores indicate more satisfaction with each of the dimensions

The reasons for the marked difference in findings between our study and that of Bevan and colleagues are unclear. The deteriorating working conditions in the prison sector highlighted above are likely to have contributed to the more negative findings in our study. It should be acknowledged, however, that we sampled trade union members and those who were most unhappy with their working conditions might have been more motivated to participate.

Nonetheless, this is the case with all cross-sectional research and it could equally be argued that the healthy worker effect (where officers who were less healthy and/or unable to cope with the pressures of the job will have left) may mean that the findings underestimate the 'true' level of hazards in the sector.

\section{Mental health in the prison service <a>}

As mentioned earlier in this chapter, there is evidence that the mental health of prison officers is a cause for concern. They are at particular risk of burnout, a state of physical and/or psychological exhaustion associated with excessive and prolonged experience of stress (Finney et al., 2013; Gould et al., 2013). Burnout has been associated with low job satisfaction and commitment and high absenteeism and turnover among officers (Carlson \& Thomas, 2006; Finney et al., 2013; Lambert et al., 2010; Schaufeli \& Peeters, 2000) as well 
as counter-productive attitudes and behaviours. For example, there is evidence that the depersonalization and feelings of ineffectiveness at work characterized by burnout can encourage them to hold more punitive attitudes towards prisoners (Lambert et al., 2010).

Studies of prison officers have also examined the incidence of mental health problems. Our study (Kinman et al., 2016) found that 72 per cent of the sample met the criteria for 'caseness', indicating that some intervention is appropriate. Levels of anxiety and insomnia, somatic symptoms and social dysfunction were all high. Walker et al. (2015) reported 95 per cent caseness in their sample of 57 officers working in an English therapeutic prison. Both studies suggest that the mental health of prison officers is considerably poorer than other occupational groups (see Goodwin et al., 2013). As with burnout, discussed above, mental health problems increase the risk of absenteeism and turnover and impair job performance (Lerner \& Henke, 2008). The GHQ has been used in many occupational studies and is considered valid for this purpose (Jackson, 2007). It has been argued, however, that occupationally-specific studies can encourage the over-reporting of mental health problems as participants seek to improve their terms and conditions of employment (Goodwin et al., 2013), so some caution may be needed when interpreting our findings. Nonetheless, there is evidence that reporting poor mental health is stigmatised, particularly in "macho" jobs such as within the prison service (Iversen et al., 2011), suggesting that the level found in our study may be under-estimated. Indeed, in our survey few participants reported being able to talk to their line managers about problems they were experiencing (Kinman et al., 2014). It seems clear, that urgent action is required to address the high level of burnout and mental health problems in prison officers to protect the wellbeing of staff, optimise staffing levels and ensure the safety of prisoners.

\section{Individual differences <a>}

Although there is evidence that the occupational and organizational factors discussed in this chapter can contribute to stress and burnout in prison officers, not everyone will respond in 
the same way. Demographic and other individual difference factors will influence the extent to which officers will respond to their work environment. The role of job experience is mixed, with some studies finding that officers who have worked longer in the role report better wellbeing (Dollard \& Winefield, 1998; Morgan et al., 2002) while others find no significant effects (Lambert et al., 2015). There is also little evidence for gender differences in stress and burnout risk among prison officers (Griffin, 2006) but women may cope with job-related stress differently to men. For example, a study conducted by Hurst and Hurst (1997) found that women officers were more likely to seek social support, whereas men typically coped by problem-solving. As discussed above in relation to the healthy worker effect, officers who are less able to cope with the demands of prison work may be more likely to leave, meaning that those remaining are unusually robust. An examination of coping style in predicting wellbeing can identify useful strategies to help develop officers' resilience. Problem or task-focused coping has been positively associated with personal accomplishment and negatively with emotional exhaustion among officers, whereas the role of emotion-focused coping is mixed and inconclusive (Cieslak et al., 2008; Gould et al., 2013).

When examining the role of demographic factors in predicting the wellbeing of prison officers, it should be acknowledged that our sample (like many other studies) comprised mainly white, middle-aged males. As of March 2018, women formed 38 per cent of the workforce in public sector prisons and 6 per cent of staff were from Black, Asian and Minority Ethnic (BAME) backgrounds (Ministry of Justice, 2018b). A lack of ethnic diversity in the prison service has been identified as contributing to an "us and them" culture (Lammy, 2017), but the role of ethnicity has been little explored. A meta-analysis by Dowden and Tellier (2004) found that BAME prison officers experienced less stress than their white counterparts, which was attributed to there being greater "understanding" between staff and prisoners (many of whom are from BAME backgrounds). Nonetheless, only two of the 191 studies reviewed were conducted outside North America, so research that examines the role of ethnicity under present working conditions is required. 


\section{Work-life balance and recovery $<a>$}

The relationship between work and personal life is crucial in predicting wellbeing.

Considerable attention has been given to work-life conflict, where the cumulative demands of roles within work and personal life are incompatible so that involvement in one role is made more difficult by participation in the other. Greenhaus and Beutell (1985) proposed three forms of work-life conflict: time (i.e. where time spent in one role limits time available to spend in another), strain (i.e. where negative emotional reactions to one role affects an individual's wellbeing and functioning in another), and behaviour (i.e. where behaviours required in one role are not appropriate for another). Work-life conflict in general has been associated with a range of negative outcomes such as stress, fatigue and burnout as well as turnover intentions and job dissatisfaction (Amstad et al., 2011).

Surprisingly little research has examined work-life conflict in correctional officers, but there is some evidence that they are particularly susceptible, and this can impair wellbeing and functioning in both domains (Armstrong et al., 2015; Hogan et al., 2006). Officers are more likely to experience conflict between work and personal life when they experience role stress at work and when they perceive their work to be dangerous (Hogan et al., 2006; Lambert et al., 2015). Our research found that prison officers experienced all three types of work-life conflict, with time-based conflict being particularly frequent (Kinman et al., 2016). Demands relating to workload, pace of work and working hours and experiences of aggression were strong predictors of work-life conflict that, in turn, was significantly linked with emotional exhaustion.

Adequate recovery from work is crucial for wellbeing, as disengagement (both physical and psychological) allows individuals to reset their functional systems to pre-stressor levels (Sonnentag \& Fritz, 2007). There is evidence that recovery experiences moderate the impact of job demands on wellbeing and the ability to "switch off" from work is an important resource. Utilising the work-home resources model (Ten Brummelhuis \& Bakker, 2012), our 
research examined the role that rumination (dwelling on negative experiences) and detachment (disengagement from work) played in emotional exhaustion experienced by prison officers (Kinman et al., 2016). We found that rumination exacerbated the impact of job demands and aggression on emotional exhaustion, whereas the ability to switch off from work concerns was protective. Our findings indicate that attention is needed to reducing work demands and providing effective support after aggressive incidents. There is evidence that prison officers who experience more emotional demands at work and find it more difficult to stop ruminating about work concerns are more likely to use alcohol to cope (Shepherd et al., 2018). Interventions are clearly needed to help prison officers develop more effective physical and psychological barriers between work and personal life to help them detach from work concerns.

\section{Presenteeism <a>}

As discussed above, working in prisons can impair both physical and psychological ill-health; unsurprisingly, sickness absence is comparatively high. Recovery from sickness is crucial, but this may be threatened by presenteeism, which refers to the act of going to work while unwell (Johns, 2010). Presenteeism is thought to be more common in male-dominated working cultures, where "giving in" to illness is a sign of weakness, and in jobs fostering a strong sense of duty and responsibility for the welfare of others (Chambers et al., 2017; Hansen \& Andersen, 2008). The type and severity of illness will clearly influence whether people can continue working, but several other factors have been associated with presenteeism (Miraglia \& Kinman, 2017).

Our research asked prison officers if they ever worked while sick and, if so, why. Eighty-four per cent of our sample reported presenteeism at least sometimes, while 53 per cent indicated that they always did so (Kinman et al., In Press). Thematic content analysis found six linked themes that underpinned presenteeism in this sector: a) punitive absence management systems, where taking sick leave was believed to be frowned upon or even 
stigmatised; b) pressure from management where many felt that continuing to work was less stressful than taking time off; c) short-staffing, leading to fears for the safety of colleagues and concerns about burdening those who were already struggling; d) job insecurity and fear of dismissal, where anxiety about being disciplined for a poor sick record encouraged presenteeism; e) fear of disbelief and shaming, where illness may not be considered a legitimate reason for absence, or people feared being seen as faking or exaggerating sickness; and f) duty and professionalism, where people worked while sick due to a strong sense of duty and loyalty to co-workers and inmates.

Our respondents acknowledged the negative impact of sick-leave on the safe functioning of prisons and generally agreed that controls were required to ensure that any absence was genuine. Nonetheless, although operational imperatives may over-ride long-term concerns for employees' wellbeing, taking time off sick to recover from legitimate and debilitating illness should be considered responsible behaviour on the part of employees and encouraged by managers. There is growing evidence for the negative impact of presenteeism on job performance, especially where work is safety-critical (Niven \& Ciborowska, 2015), so it is vital to raise awareness of the risks of presenteeism for the wellbeing of staff and the safe functioning of prisons.

\section{Interventions <a>}

Few studies have evaluated stress-reduction interventions in prison officers. McCraty et al. (2009) reported the findings of a successful case-controlled initiative that included several modules such as identifying risk factors for health, refocusing and restructuring emotions, biofeedback, enhancing communication skills, and how to apply the skills learned in the workplace. Three months post-intervention, improvements were found for prison officers on physical markers of health, such as cholesterol, heart rate and blood pressure, and a reduction in self-reported emotional distress was also observed. Perceptions of support, motivation, goal clarity and productivity also improved in the intervention group. More 
recently, Dugan et al. (2016) used participatory action research to compare the effects of two methods of delivering health and safety interventions in US correctional facilities; the first initiative was 'top-down' (driven by administrators assisted by health professionals); and the second was 'bottom up' (developed by frontline officers themselves). Both programmes had mixed success, with the authors noting that setting simple and achievable targets and ensuring continuity through regular meetings were particularly important. Management support and the availability of funding were also among the challenges encountered, with managers sometimes discouraging the implementation of interventions due to security concerns and other operational reasons.

There is a clear need for more research on interventions within the prison service to inform initiatives that help improve the wellbeing of officers. Longitudinal research that examines some of the associations highlighted in this chapter could help guide such interventions. We recommend a risk management approach, drawing on approaches such as the HSE Management Standards (HSE, 2017) set out in this chapter that seek to identify work-related stress at its source. A systemic approach to improving wellbeing in the sector is, however, crucial as prison officers will understandably be reluctant to engage with interventions that merely seek to improve their resilience and coping skills rather than address the structural causes of their distress. For example, while our findings suggest that strategies to help officers reduce rumination would alleviate emotional exhaustion and aid recovery, such individual-level interventions should not be at the expense of addressing the root causes of stress, such as short-staffing, overcrowding and increased violence.

Although various primary, secondary and tertiary stress management options are available, programmes should be tailored to the unique challenges faced by correctional institutions and the people working within them. Dugan et al. (2016) have highlighted the importance of considering the hierarchical nature of prison work, as interventions incompatible with this are unlikely to succeed. Although some types of intervention are likely to be effective in all types of prisons (for example ensuring adequate staffing levels and providing training in reducing 
rumination), officers working in high security institutions may have different needs to those employed in open prisons.

Action is needed at the policy level, such as reducing the use of incarceration to tackle prison over-crowding, at the organizational level, such as ensuring adequate staffing levels, as well as at the individual level, for example, stress management training. Organizational and individual level interventions can be complementary (LaMontagne et al., 2007) and there is potential for secondary-level interventions to enhance the responsiveness of employees to organizational initiatives (Bond et al., 2008). It is important to recognise the systemic nature of organizations, as aspects of the job, the working environment and the individual worker will influence each other. For example, evidence that managers pressure officers to work while sick will be related to operational concerns about short-staffing. Such techniques may be effective in ensuring cover in the short-term but will impact on the health and safety of staff and inmates and incur greater long-term costs than increasing staffing levels. Moreover, prison officer burnout can encourage more punitive attitudes towards prisoners, which will inevitably impact on the psychological climate of prisons and inmate behaviour. The first step is for prison leaders to recognise the financial and organizational benefits of wellbeing programmes, identify challenges to their successful implementation and potential solutions. Trounson and Pfeifer (2016) have provided some guidelines for correctional institutions that are developing interventions to enhance staff wellbeing. Several steps are recommended with employee participation being fundamental at each stage: a) defining wellbeing as it relates to the organization; b) demonstrating the need for improvement by comparing the wellbeing needs of staff with the initiatives currently available; $c$ ) ensuring that the programme is congruent with the needs of staff and the organization and supported by research evidence; d) measuring the impact of interventions using appropriate tools; e) piloting the programme; f) making changes where necessary; and g) rolling the programme out to the wider organization and continually monitoring its effectiveness. 


\section{Conclusions <a>}

This chapter provides evidence that the prison service in the UK is currently experiencing a crisis that has increased employees' exposure to psychosocial stressors such as job demands, low control and a lack of support. New threats to the wellbeing of prison staff, such as the use of NPS and an increase in overcrowding, self-harm and violence among the incarcerated population, are likely to compound the risks of job-related stress, burnout and mental health problems that are already higher than in many other professional groups. At the same time, managers' attempts to optimise staffing levels may exacerbate the demands on staff by encouraging presenteeism, further increasing the risk of burnout among their staff. As well as contributing to staff turnover, the performance of officers remaining in the job is likely to suffer and the safety of correctional facilities is likely to deteriorate. To address these challenges, a multi-level approach is required with the input of policy-makers, employers, management and officers themselves. While stress management training should be part of such an approach, individually-focused initiatives will not in themselves be sufficient. The need to consider policy (for example, incarceration strategies) suggests that a multi-disciplinary approach would be effective, where experts in crime, rehabilitation and policy work together with occupational health psychologists to identify systemic and sustainable solutions to the current crisis.

\section{References <a>}

Amstad, F.T., L.L. Meier, U. Fasel, A. Elfering, and N.K. Semmer, N.K. (2011), 'A metaanalysis of work-family conflict and various outcomes with a special emphasis on crossdomain versus matching-domain relations', Journal of Occupational Health Psychology, 16 (2), 151-169.

Armstrong, G. S., C.A. Atkin-Plunk, and J. Wells (2015), 'The relationship between workfamily conflict, correctional officer job stress, and job satisfaction', Criminal Justice and Behavior, 42, 1066-1082. 
Bevan, A., J. Houdmont, and N. Menear, N. (2010), 'The Management Standards Indicator Tool and the estimation of risk', Occupational Medicine, 60, 525-531.

Bond, F.W., P.E. Flaxman, and D. Bunce (2008), 'The influence of psychological flexibility on work redesign: Mediated moderation of a work reorganization intervention', Journal of Applied Psychology, 93 (3), 645-654.

Boudoukha, A.H., E. Altintas, S. Rusinek, C. Fantini-Hauwel, and M. Hautekeete (2013), 'Inmates-to-staff assaults, PTSD and burnout: Profiles of risk and vulnerability', Journal of Interpersonal Violence, 28 (11), 2332-2350.

Carlson, J.R., and T. Thomas (2006), 'Burnout among prison case workers and corrections officers', Journal of Offender Rehabilitation, 43 (3), 19-34.

Chambers, C., C. Frampton, and M. Barclay (2017), 'Presenteeism in the New Zealand senior medical workforce - a mixed-methods analysis', The New Zealand Medical Journal, 130 (1449), 10-21.

Cieslak, R., J. Korczynska, J. Strelau, and M. Kaczmarek (2008), 'Burnout predictors among prison officers: The moderating effect of temperamental endurance', Personality and Individual Differences, 45, 666-672.

Cousins, R., C.J. Mackay, S.D. Clarke, C. Kelly, P.J. Kelly, and R.J. McCaig, (2004), “Management Standards' and work-related stress in the UK: Practical development', Work \& Stress, 18 (2), 113-136.

Crawley, E.M. (2004), 'Emotion and performance: Prison officers and the presentation of self in prisons', Punishment \& Society, 6 (4), 411-427.

Crown Prosecution Service (2018), Prison-related offences, accessed 8 August 2018 at https://www.cps.gov.uk/legal-guidance/prison-related-offences-0.

Denhof, M.D. and C.G. Spinaris (2013), 'Depression, PTSD, and comorbidity in United States corrections professionals: Prevalence and impact on health functioning', Desert 
Waters Correctional Outreach, accessed 17 October 2018 at http://desertwaters.com/wpcontent/uploads/2013/08/Corrections-Fatigue-Model-Attachment-Document.pdf.

Dollard, M.F. and A.H. Winefeld (1998), 'A test of the demand-control/support model of work stress in correctional officers', Journal of Occupational Health Psychology, 3 (3), 243-264.

Dowden, C., and C. Tellier (2004), 'Predicting work-related stress in correctional officers: A meta-analysis', Journal of Criminal Justice, 32, 31-47.

Dugan, A.G., D.A. Farr, S. Namazi, R.A. Henning, K.N. Wallace, M.E. Ghaziri, L. Punnett, J.L. Dussetschleger, and M.G. Cherniack, (2016), 'Process evaluation of two participatory approaches: Implementing Total Worker Health $\AA^{\circledR}$ interventions in a correctional workforce', American Journal of Industrial Medicine, 59, 897-918.

Edwards, J.A., S. Webster, D. van Laar, and S. Easton (2008), 'Psychometric analysis of the UK Health and Safety Executive's Management Standards work-related stress Indicator Tool', Work \& Stress, 22 (2), 96-107.

Finney, C., E. Stergiopoulos, J. Hensel, S. Bonato, and C. Dewa (2013), 'Organizational stressors associated with job stress and burnout in correctional officers: A systematic review', BMC Public Health, 13, 82

Fritz, C., L.B. Hammer, F. Guros, B.R. Shepherd, and D. Meier (2018), 'On guard: The costs of work-related hypervigilance in the correctional setting', Occupational Health Science, 2 (1), 67-82.

Goldberg, D.P. (1978), 'Manual of the General Health Questionnaire', Windsor: NFER Goodwin, L., I. Ben-Zion, N.T. Fear, M. Hotopf, S.A. Stansfeld, and S. Wessely (2013), 'Are reports of psychological stress higher in occupational studies? A systematic review across occupational and population based studies', PLOS ONE, 8 (11), 1-22.

Gordon, J., and T. Baker (2017), 'Examining correctional officers' fear of victimization by inmates: The influence of fear facilitators and fear inhibitors', Criminal Justice Policy Review, 28 (5), $462-487$. 
Gould, D.D., S.L. Watson, S.R. Price, and P.M. Valliant (2013), 'The relationship between burnout and coping in adult and young offender center correctional officers: An exploratory investigation', Psychological Services, 10 (1), 37-47.

Greenhaus, J.H. and N.J. Beutell (1985), 'Sources of conflict between work and family roles', Academy of Management, 10 (1), 76-88.

Griffin, M.L. (2006), 'Gender and stress: A comparative assessment of sources of stress among correctional officers', Journal of Contemporary Criminal Justice, 22 (1), 4-25.

Hansen, C.D. and J.H. Andersen (2008), 'Going ill to work - What personal circumstances, attitudes and work-related factors are associated with sickness presenteeism?', Social Science \& Medicine, 67, 956-964.

Health and Safety Executive [HSE] (2017) Tackling work-related stress using the Management Standards approach: a step-by-step approach, accessed 21 July 2018 at http://www.hse.gov.uk/pubns/wbk01.pdf.

HM Chief Inspector of Prisons for England and Wales (2016), Annual report 2015-16, London: Stationary office

HM Chief Inspector of Prisons for England and Wales (2018), Annual report 2017-18, London: Stationary office

Hogan, N.L., E.G. Lambert, M. Jenkins, and S. Wambold (2006), 'The impact of occupational stressors on correctional staff organizational commitment: A preliminary study', Journal of Contemporary Criminal Justice, 22 (1), 44-62.

House of Commons Library (2018), UK prison population statistics, London: Stationary office Hurst, T., and M. Hurst (1997), 'Gender differences in mediation of severe occupational stress among correctional officers', American Journal of Criminal Justice, 22, 121-137. 
Iversen, A.C., L. van Staden, J.H. Hughes, N. Greenberg, M. Hotopf, R.J. Rona, G.

Thornicroft, S. Wessely, and N.T. Fear (2011), 'The stigma of mental health problems and other barriers to care in the UK Armed Forces', BMC Health Services Research, 11, 1-10. Jackson, C. (2007), 'The General Health Questionnaire', Occupational Medicine, 57, 79. James, L., and N. Todak (2018), 'Prison employment and post-traumatic stress disorder: Risk and protective factors', American Journal of Industrial Medicine, 61, 725-732.

Johns, G. (2010), 'Presenteeism in the workplace: A review and research agenda', Journal of Organizational Behavior, 31, 519-542.

Johnson, S., C. Cooper, S. Cartwright, I. Donald, P. Taylor, and C. Millet, C. (2005), 'The experience of work-related stress across occupations', Journal of Managerial Psychology, 20, 178-187.

Kinman, G., A. Clements, and J. Hart (2014), Work-related Wellbeing in the Prison Service, UK: POA Publications.

Kinman, G., A.J. Clements, and J. Hart (2016), 'Work-related wellbeing in prison officers: A benchmarking approach', International Journal of Workplace Health Management, 9 (3), 290-307.

Kinman, G., A.J. Clements, and J. Hart (2017), 'Job demands, resources and mental health in UK prison officers', Occupational Medicine, 67 (6), 456-460.

Kinman, G., A.J. Clements, and J. Hart (In Press), "'When are you coming back?" Presenteeism in UK prison officers', The Prison Journal

Kunst, M.J.J. (2011), 'Woking in prisons: A critical review of stress in the occupation of correctional offiers', in J. Langan-Fox \& C.L. Cooper (eds), Handbook of stress in the occupations, Cheltenham, UK: Edward Elgar, pp. 241-283. 
Lambert, E.G., I. Altheimer, N.L. Hogan, and S.M. Barton-Bellessa (2011), 'Correlates of correctional orientation in a treatment-oriented prison: A partial test of person-environment fit theory', Criminal Justice and Behavior, 38 (5), 453-470.

Lambert, E.G., N.L. Hogan, I. Altheimer, S. Jiang, and M.T. Stevenson (2010), 'The relationship between burnout and support for punishment and treatment: A preliminary examination', International Journal of Offender Therapy and Comparative Criminology, 54 (6), 1004-1022.

Lambert, E.G., K.I. Minor, J.B. Wells, and N.L. Hogan (2015), 'Leave your job at work: The possible antecedents of work-family conflict among correctional staff', The Prison Journal, 95 (1), 114-134.

Lammy, D. (2017) The Lammy review: An independent review into the treatment of, and outcomes for, Black, Asian and Minority Ethnic individuals in the Criminal Justice System, accessed 9 August 2018 at https://www.gov.uk/government/publications/lammy-review-finalreport.

LaMontagne, A.D., T. Keegel, A.M. Louie, A. Ostry, and P.A. Landsbergis (2007), 'A systematic review of the job-stress intervention evaluation literature 1990-2005', International Journal of Occupational and Environmental Health, 13, 269-280.

Lerner, D. and R.M. Henke (2008), 'What does research tell us about depression, job performance, and work productivity?' Journal of Occupational and Environmental Medicine, 50 (4), 401-410.

Martin, J.L., B. Lichtenstein, R.B. Jenkot, and D.R. Forde (2012) “They can take us over any time they want": Correctional officers' responses to prison crowding', The Prison Journal, 92 (1), 88-105.

McCraty, R., M. Atkinson, L. Lipsenthal, and L. Arguelles (2009), 'New hope for correctional officers: An innovative program for reducing stress and health risks', Applied Psychophysiology and Biofeedback, 34 (4), 251-272. 
Ministry of Justice (2018a), Annual prison performance ratings 2017/18, accessed 31 July 2018 at

https://assets.publishing.service.gov.uk/government/uploads/system/uploads/attachment da ta/file/730208/annual prison performance ratings 201718 statistical bulletin.pdf.

Ministry of Justice (2018b), Her Majesty's Prison and Probation Service (HMPPS) workforce statistics bulletin, as at 31 March 2018, accessed 8 August 2018 at https://assets.publishing.service.gov.uk/government/uploads/system/uploads/attachment da ta/file/707471/annual-hmpps-workforce-statistics-31-march-2018.pdf.

Ministry of Justice (2018c), Safety in custody statistics, England and Wales: Deaths in prison custody to June 2018 assaults and self-harm to March 2018, accessed 8 August 2018 at https://assets.publishing.service.gov.uk/government/uploads/system/uploads/attachment da ta/file/729496/safety-in-custody-bulletin-2018-Q1.pdf.

Miraglia, M. and G. Kinman (2017), 'The hidden costs of working when sick', The Psychologist, 30, 36-41, accessed 16 October 2018 at thepsychologist.bps.org.uk/volume30/august-2017/hidden-costs-working-when-sick.

Misis, M., B. Kim, K. Cheeseman, N.L. Hogan, and E.G. Lambert (2013), 'The impact of correctional officer perceptions of inmates on job stress', SAGE Open, 3 (2), 1-13.

Morgan, R.D., R.A. van Haveren, and C.A. Pearson (2002), 'Correctional officer burnout: Further analyses', Criminal Justice and Behavior, 29 (2), 144-160.

Niven, K., and N. Ciborowska (2015), 'The hidden dangers of attending work while unwell: A survey study of presenteeism among pharmacists', International Journal of Stress Management, 22 (2), 207-221.

Norton, A. (2016), 'Spicing up the subject' The recorded experiences of prisoners and prison staff on the subject: New psychoactive substance use in a North West prison, accessed 26 January 2019 at https://howardleague.org/wp-content/uploads/2017/01/Spicing-up-thesubject.pdf. 
Nylander, P.A., O. Lindberg, and A. Bruhn (2011), ‘Emotional labour and emotional strain among Swedish prison officers', European Journal of Criminology, 8 (6), 469-483.

Prison Reform Trust (2017), Bromley briefings prison factfile Autumn 2017, accessed 20 August 2018 at

http://www.prisonreformtrust.org.uk/Portals/0/Documents/Bromley\%20Briefings/Autumn\%20

\section{7\%20factfile.pdf.}

Ralphs, R., L. Williams, R. Askew, A. Norton (2017), 'Adding Spice to the Porridge: The development of a synthetic cannabinoid market in an English prison', International Journal of Drugs Policy, 40, 57-69.

Schaufeli, W. B., and M.C. Peeters (2000), 'Job stress and burnout among correctional officers: A literature review', International Journal of Stress Management, 7, 19-48.

Shepherd, B.R., C. Fritz, L.B. Hammer, F. Guros, and D. Meier (2018), 'Emotional demands and alcohol use in corrections: A moderated mediation model', Journal of Occupational Health Psychology, http://dx.doi.org/10.1037/ocp0000114

Sonnentag, S., and C. Fritz (2007), 'The Recovery Experience Questionnaire: Development and validation of a measure for assessing recuperation and unwinding from work', Journal of Occupational Health Psychology, 12, 204-221.

Steiner, B. and J. Wooldredge (2015), 'Individual and Environmental Sources of Work Stress Among Prison Officers', Criminal Justice and Behavior, 42 (8), 800-818.

Stichman, A.J., and J.A. Gordon (2014), 'A preliminary investigation of the effect of correctional officers' bases of power on their fear and risk of victimization', Journal of Crime and Justice, 38 (4), 1-16.

Ten Brummelhuis, L. L., and A.B. Bakker (2012), 'A resource perspective on the work-home interface: The work-home resources model', American Psychologist, 67, 545-556. 
Trounson, J. S., and J.E. Pfeifer (2016), 'Promoting correctional officer wellbeing: Guidelines and suggestions for developing psychological training programs', Advancing Corrections, 1, 56-64. Vickovic, S. G., M.L. Griffin, and H.F. Fradella (2013), 'Depictions of correctional officers in newspaper media: an ethnographic content analysis', Criminal Justice Studies, 26 (4), 455477.

Walker, E.J., C.A. Jackson, H.H. Egan, and M. Tonkin (2015), 'Workability and mental wellbeing among therapeutic prison officers', Occupational Medicine, 65, 549-551.

Webster, S. and T. Buckley (2008), Psychosocial Working Conditions in Britain in 2008, Sudbury: HSE Books

Wright, L., J. Borrill, R. Teers, and T. Cassidy (2006), 'The mental health consequences of dealing with self-inflicted death in custody', Counselling Psychology Quarterly, 19 (2), 165180. 